conducted in public is no bad thing in a public service and may also help to make the public aware of the complexities of many of the issues.

Every employee should, however, have the right to blow the whistle when all else fails. There sometimes comes a point when doctors and others must draw public attention to iniquities. Some of what has been happening in Britain's special hospitals and prisons provides good examples of where whistle blowing was needed. In circumstances where the public gain from whistleblowing is substantial the law should offer protection - as in the United States.. ${ }^{3}$
Although we need legal reform, the main message is that managers worried about whistle blowing should concentrate their energies on improving the management in their institutions rather than on trying to gag staff. Similarly, staff should insist first on good management and only secondly on the right to blow the whistle-because whistle blowing usually achieves little.

Editor, $B M \mathcal{F}$

RICHARD SMITH

1 Walker A. Interleukin 2 denied on grounds of cost. BMF 1991;302:372-3.

2 Smith R. Christie Hospital reports on interleukin 2 controversy. BM7 1991;302:1041.

3 Greene D, Cooper J. Whistle blowers. BM7 1992;305:1343-4.

\title{
Gangliosides and neurological diseases
}

\section{Their use in humans should be suspended}

Gangliosides are found mainly in nerve cells but also occur in smaller concentrations in other cell types. They belong to the family of complex acidic glycosphingolipids and make up about a tenth of the total lipid content of the nerve cell plasmalemma. These complex glycolipids are formed in the Golgi apparatus of the cell, transported down the axon, and from there incorporated into the lipid bilayer of the axolemma. A complete understanding of their normal role and function is not yet available, but they are likely to be involved in signalling between cells. The ganglioside $\mathrm{G}_{\mathrm{ml}}$ acts as a cell surface receptor for cholera toxin.

Exogenous gangliosides help in the regeneration of peripheral nerves, enhance formation of neuromuscular junctions, and promote neuronal sprouting. They also increase peripheral nerve enzymes such as sodium and potassium ATPase, adenylate cyclase, and phosphodiesterase. In the gangliosidoses the metabolism of gangliosides is clearly abnormal, and evidence is accruing of their involvement in many neurological diseases (for example, multiple sclerosis ${ }^{1}$ ).

Antibodies to gangliosides, particularly to the $\mathrm{G}_{\mathrm{m} 1}^{*}$ ganglioside, are present in the serum of patients with many different diseases. High titres of antibodies to $G_{m l}$ have been found in patients with motor neuropathies, especially multifocal motor neuropathy (a clinical syndrome of asymmetric limb weakness with neurophysiological evidence of motor conduction block and axonal loss). Claims have been made that these patients may benefit from immunosuppressive treatment. ${ }^{2}$ The antibodies are clearly not specific-similar high titres have been found in patients with such diverse neuropathies as chronic inflammatory demyelinating polyneuropathy, Guillain-Barré polyneuritis, and other lower motor neurone syndromes. They have also been found in patients with autoimmune disorders of muscle and even in normal people. ${ }^{3}$

The techniques of measuring these antibodies are relatively new, and even "minor methodologic variations can lead to large changes in results." Investigations have shown that the antibodies react with a limited range of epitopes, usually on gangliosides $G_{m 1}$, although cross reactivity with other gangliosides occurs. The antibody specificities and their possible relation to different diseases remain to be determined. What emerges from the studies is the suggestion that high antibody titres may be clinically important, but no firm conclusions can yet be drawn.

Gangliosides have been used to treat many neurological diseases. By 1990 more than 12 million patients around the world had received them. ${ }^{5}$ Usually prepared from bovine brains, they have been used to treat patients with conditions as diverse as diabetic and alcoholic neuropathies, nerve injuries, dementia, Parkinson's disease, and cerebrovascular disorders. ${ }^{5}$ An effect of the monosialoganglioside $G_{m 1}$ has been claimed in animals with nigrostriatal lesions. Originally thought to be due to enhanced sprouting, the effect is now considered to be a neuroprotective mechanism. Similar effects have been claimed to occur after treatment for injury to the white matter (for example, in optic nerve lesions ${ }^{6}$ and acute injuries to the spinal cord, where considerable improvements in motor performance have followed treatment with gangliosides ${ }^{7}$ ). Similarly, treatment with gangliosides has been claimed to benefit animals with induced dopamine deficiency. ${ }^{8}$ Recent evidence suggests that they are effective only when given shortly after injury, ${ }^{9}$ which may explain their lack of efficacy in genetically determined disorders of the central nervous system. ${ }^{5}$

How gangliosides may bring about such therapeutic effects is unknown, but some studies have suggested that they may interact with endogenous trophic factors and counteract the toxicity of certain excitatory amino acids. ${ }^{10}$

Despite the accumulating claims for their therapeutic benefits gangliosides should be used extremely cautiously until more knowledge is available. This caveat is highlighted by this week's report by Figeuras $e t$ al of the development of serious complications in patients treated with gangliosides (p 1330). ${ }^{11}$ Because these substances are immunogenic (with a role in producing a disease resembling experimental allergic encephalomyelitis in immunised animals ${ }^{12}$ ) and their therapeutic value is disputed further trials and experimentation in patients, if still continuing, should be suspended. Indeed, much better research in animals needs to be done on the normal and pathological function of gangliosides before they should be allowed any therapeutic role.

PETER O BEHAN Professor of Clinical Neurology

B A G HANIFFAH

University Department of Neurology, Lecturer in Neurology

Institute of Neurological Sciences,

Southern General Hospital,

Glasgow G51 4TF

1 Yu RK, Ledeen RW, Eng LF. Ganglioside abnormalities in multiple sclerosis. $\mathcal{f}$ Neurochem 1974;23:169-74.

2 Pestronk A, Cornblath DR, Ilyas AA, Baba H, Quarles RH, Griffin JW, et al. A treatable multifocal motor neuropathy with antibodies to GMl ganglioside. Ann Neurol 1988;24:73-8.

3 Gregson NA, Jones D, Thomas PK, Willison HJ. Acute motor neuropathy with antibodies to GMI ganglioside. F Neurol 1991;238:447-51. 
4 Marcus DM, Latov N, Hsi BP, Gillard BK. Measurement significance of antibodies against $\mathrm{G}_{\mathrm{m}}$ ganglioside. F Neuroimmunol 1989;25:155-9.

5 Bradley WG. Critical review of gangliosides and thyrotropin-releasing hormone in peripheral neuromuscular diseases. Muscle and Nerve 1990;13:833-42.

6 Sautter J, Schwartz M, Duvdevani R, Sabel BA. GMI ganglioside treatment reduces visual deficits fter graded rush of the rat optic nerve. Brain Res 1991;565:23-33.

7 Geisler FH, Dorsey FC, Coleman WP. Recovery of motor function after spinal cord injury, randomized placebo controlled trial with GM1 gangliosides. N Engl f Med 1991;324:1829-38.

8 Schneider JS, Pope A, Simpson K, Taggart J, Smith MG, DiStefano L. Recovery from experimental parkinsonism in primates with $\mathrm{G}_{\mathrm{M} 1}$ ganglioside treatment. Science 1992;256:843-6.
9 Ramirez JJ, Sabel BA. Toward a unified theory of ganglioside mediated functional restoration after brain injury: lesion size, not lesion site, is the primary factor determing efficacy. Acta Neurobiol 1990;50:415-38.

10 Sabel BA. Gangliosides and brain repair. Neuroscience Facts 1992;3:83-4.

11 Figeuras A, Morales-Olivas FJ, Capella D, Palop V, Laporte J-R. Bovine gangliosides and acute motor polyneuropathy. BMF 1992;305:1330-1

12 Nagai $Y$, Momoi T, Saito M, Mitsuzawa E, Ohtani S. Ganglioside syndrome, a new autoimmune neurologic disorder, experimentally induced with brain gangliosides. Neurosci Lett 1976;2 $107-11$

\section{The patient's charter and the triage nurse}

\section{Done properly, nurse triage can halve waiting times in $A \mathcal{E} E$}

Standards set in the patient's charter for waiting times in accident and emergency departments have put the role of the triage nurse under the spotlight. The standard "You will be seen immediately and your need for treatment assessed"1 covers the traditional function of triage (from the French, sorting out). This includes assessing patients, providing first aid, deciding priorities, controlling the flow of patients, initiating diagnostic procedures, and liaising with other health care professionals and relatives. ${ }^{2-7}$ None of this is new, but the effectiveness of triage nurses has recently been challenged. ${ }^{8}$

Although there are contrary findings, research has shown that a system of nurse triage can significantly reduce waiting times when performed effectively. ${ }^{9}$ Studies that have not shown this, such as one by George et al, ${ }^{8}$ have been based on a narrow definition of nurse triage and have not included other factors important to an effective system, such as staffing and departmental layout.

The whole system within which nurse triage operates is crucial to its success. Slater has shown the benefits of having two triage nurses, one for seriously ill and one for ambulant patients, each seeing patients in different areas. This method halves the waiting times for acutely ill patients. ${ }^{10}$ Shields also suggested that ambulant patients should be seen in a separate area from the acutely ill; again treatment delays were halved. ${ }^{11}$ Separating out patients without acute problems improves the use of emergency facilities and staff. Debates continue over whether nurse triage needs to operate throughout the whole day to improve waiting times or whether it works when used only for short periods.

Clearly the workload of the department, its layout, the amount of major trauma, and seasonal peaks and troughs all affect the number of nurses needed for triage. Education is also crucial for the success of the system, and proper preparation of the triage nurse must be built into the implementation and continuing evaluation of the system. Nuttall suggested that training should include a period of observation and practical experience under the direction of an experienced triage nurse. ${ }^{9}$

Nurse triage seems the preferred way of addressing the standard on immediate assessment for the patient's charter. The effectiveness of the delivery of any standard needs to be evaluated by well structured, valid, and reliable studies. Those studies that have met these criteria suggest that nurse triage is effective. Importantly, nurse triage seems to increase patients' satisfaction as well.

TOM KEIGHLEY Director of Nursing and Quality

JAN MAYCOCK Acting Assistant Regional Director (Quality)

Yorkshire Regional Health Authority, Harrogate HG1 5AH

1 Department of Health. The patient's charter. London: DoH, 1992.

Mallett J. Triage in accident and emergency departments. Fournal of Advanced Nursing 1992;15:1443-51.

3 Bailey A, Hallam K, Hirst K. Triage on trial. Nursing Times 1987;83:65-6.

4 Buckles E. Advanced trauma life support. Nursing Standard 1990;4:54-5.

5 Carew-McColl M, Buckles E. A workload shared. Health Service fournal 1990;100:27.

6 Harris B, Fox J. Eye opener at Bristol. Health Service fournal 1986;96:364-5.

7 Jones G. Top priority. Nursing Standard 1988,3:28.9.

7 Jones G. Top priority. Nursing Standard 1988;3:28-9. a British accident and emergency department. BMf 1992;304:876-8.

a British accident and emergency department. BMF 1992;304:8
Nuttall $M$. The chaos controller. Nursing Times 1982:20:656-8.

10 Slater R. Triage nurse in the emergency department. American fournal of Nursing 1970;70:127-9.

10 Slater R. Triage nurse in the emergency department. American foumal of Nursing 1970;70:127-9. Nursing 1976;2:37-41. 